\title{
COVID-19: High Risk Groups for COVID-19 and Challenges for Medical Universities
}

\author{
Oral A. Ataniyazova
}

Medical University of Karakalpakstan, Uzbekistan.

\begin{abstract}
COVID-19 as a global pandemic created a new challenges to all countries in the world. Since 18 March 2020 there is cases of COVID-19 in Uzbekistan and in collaboration with WHO all medical society were prepared and trained under International standards in order provide adequate medical services to people. In order to better organize medical services to COVID-19 patients it is very important to clarify people with the high risk to COVID-19 and prioritize their treatment and prevention. Number of recent research and data was investigated and adopted to local condition of Uzbekistan. But still there is a group of people, which could be at the higher risk for COVID-19 than others. During decades the Republic of Karakalpakstan (in Uzbekistan) considered as the epicenter of the Aral Sea crisis with high level pollution. High level of Tuberculosis (TB), anemia, cancer and other diseases was discovered among local population. Our previous investigation has shown disorders in the immune, endocrine systems and other pathologies in women and children of this region. So the patients with TB and anemia, as well cancer and HIV considered the highest risk groups for COVID-19. The COVID-19 pandemic also affected education system in general. But it is especially very important to consider at the Higher medical education system in order to better organize education and practice for medical students, organize the activities of the teaching staff, improve capacity of the clinics, research and international collaboration.
\end{abstract}

Keywords: COVID-19- Higher medical education- Aral sea crisis- TB- Anemia- Cancer

Asian Pac Environ Cancer, 3 (Suppl 1), 21-23

COVID-19 became a global pandemic involving more than 100 countries. It can affect any person, from children to the eldest, with symptoms ranging from very light to severe. As demonstrated in many countries about $80 \%$ of COVID-19 has a light form. Some people could have other illnesses caused by respiratory viruses or some people may be more likely to have severe illness which increases their risk. COVID-19 is a new disease and there is limited information regarding risk factors for severe disease. As CDC informed - based on currently available information and clinical expertise, older adults and people of any age who have serious underlying medical conditions might be at higher risk for severe illness from COVID-19 [1]:

The experience of COVID infected countries has shown, there are several groups of risk factors for people who are more vulnerable to Coronavirus infection [1-2]:

- People over 65 years of age;

- People who live in a nursing home or long-term care facility;
Submission Date: 06/15/2020Ａcceptance Date: 07/07/2020

- People with chronic conditions - like diabetes, heart failure, high blood pressure, oncological processes; asthma and other chronic pulmonary diseases, chronic kidney and liver diseases, and immunodeficiency;

- People with chronic kidney disease undergoing dialysis;

- People with liver disease;

- People with HIV and TB [2];

In our region people with tuberculosis are of special concern. In the Republic of Karakalpakstan (in Uzbekistan) 133 cases of coronavirus Covid-19 were recorded. Among infected people 92\% recovered and no mortality case occurred until May 21, 2020. Most of patients with Covid-19 had the light form. Due to high level and effective prophylactic measures provided by the government and the health system of Uzbekistan, using international standards (WHO) in caring and treatment of COVID-19 the implementation of a wide range of social programs, effective activities of medical doctors in

Corresponding Author:

Dr. Oral A. Ataniyazova

Medical University of Karakalpakstan, Uzbekistan.

Email: atoral@yandex.ru 
recognition of early symptoms performing wide range prophylactic measures, COVID-19 so far had only minor effects on the population level in Uzbekistan.

However, despite of effective measures, there are still high risk groups and regions for Covid-19 to consider in Uzbekistan. In that regard the general poor health condition of the population in the Aral Sea region stands out. As it is well known, the Republic of Karakalpakstan is located at the epicenter of the Aral Sea crisis and the population is affected by chronic environmental pollution such as pesticides, poor drinking water, dust pollution and others during many decades. The incidence of tuberculosis (TB), anemia, and oncological diseases is higher in Karakalpakstan than in other region of Uzbekistan and Central Asia [3-4]. Therefore, the pandemic situation with COVID-19 creates additional risk factors for the population's health in the Aral Sea region.

TB is a highly contagious respiratory disease that's been around for centuries. Like COVID-19, it attacks the lungs and causes similar symptoms, such as cough, fever and difficulty breathing. As the world struggles with the COVID-19 pandemic, it is important to ensure that essential services and operations for dealing with longstanding health problems continue to protect the lives of people with TB and other chronic diseases or health conditions. Health services, including national programs to combat TB, need to be actively engaged in ensuring an effective and rapid response to COVID-19 while ensuring that TB services are maintained.

Modelling work suggests that if the COVID-19 pandemic led to a global reduction of $25 \%$ in expected TB detection for 3 months - a realistic possibility given the levels of disruption in TB services being observed in multiple countries - then we could expect a $13 \%$ increase in TB deaths, bringing us back to the levels of TB mortality that we had 5 years ago. This may even be a conservative estimate as it does not factor in other possible impacts of the pandemic on TB transmission, treatment interruptions and poorer outcomes in people with TB and COVID-19 infection [5]. Between 2020 and 2025 an additional 1.4 million TB deaths could be registered as a direct consequence of the COVID-19 pandemic [6].

Support for uninterrupted TB preventive treatment and treatment of TB disease should be ensured alongside the COVID-19 response. It is critical that TB services are not disrupted during the COVID19 response [7].

As in all countries of the world, since March 2020, given the new rules on social distancing, traditional face-to-face teaching was replaced by distance learning (virtual) in Uzbekistan. Coronavirus pandemic creates challenges for education in general and especially for higher medical education.

In such critical condition as COVID-19 pandemic medical Universities in Uzbekistan, as well as in many countries continued teaching process, but also involved in providing consultative activities, research, training of doctors, nurses, distribute information, etc.

The staff of Medical University of Karakalpakstan was actively involved in training of doctors, nurses on COVID-19 under WHO standards in all districts of
Karakalpakstan. A special training module was developed for doctors working at intensive care departments. The teaching process was continued through an on-line system. A special on-line platform was used to cover the teaching process for all students and residents.

The main activities of University - provide qualified teaching process. However, COVID-19 pandemic created the challenges in providing a quality education process in general:

- Distance learning - in spite of the achievements there were also some problems in terms of loss of face to face contact;

- Continuation of a teaching process complying with quality standards;

- In some disciplines, also access to clinical practices and providing laboratory work was still not enough provided;

- Ability of students to be involved to teaching process - lack of computer technologies in some rural districts, lack of internet access;

- Organizing clinical practices in summer could be a problem - need to be transferred to other period;

- The action needed to support postgraduate students, including discussing and agreeing with students how they will progress their research during this period;

- Implementation of scientific research at the clinics;

- Organizing admission process to the University;

- other

The situation with COVID-19 underlines the constant need to educate medical doctors, and to pay closer attention to subjects such as microbiology, virology, infection control, sanitation and hygiene in teaching programs. That crisis acted as a call for improving the medical curriculum. Also it was important to address activities of Medical Universities in the communities in order to raise knowledge and skills of the population to support readiness for such epidemic conditions. The role of Medical Universities is paramount in such conditions. Medical universities must ensure that they keep up to date with, and carefully follow, government advice and guidance.

The Coronavirus pandemic has shown the needs for Medical Universities to improve international collaboration, develop joint scientific research projects in order to prepare qualified doctors, rapidly address population's needs and improve their health.

\section{References}

1. CDC -: National Center for Immunization and Respiratory Diseases (NCIRD), Division of Viral Diseases, May14, 2020.

2. People with HIV, TB have twice the risk of death from coronavirus. www.theglobeandmail.com.

3. Ataniyazova O. "Health and Ecological Consequences of the Aral Sea crisis". The 3-d World Water Forum Proceeding, Kyoto. 2003;:P 214-220.

4. Shona Horder, Beverly Stringer, et all. Where there is hope: a qualitative study examining patients' adherence to multidrug resistant tuberculosis treatment in Karakalpakstan, Uzbekistan. BMC Infect Dis. 2016 ; Published online 2016 Jul 28. 
5. Glaziou P. Predicted impact of the COVID-19 pandemic on global tuberculosis deaths in 2020 [Internet]. Epidemiology. 2020 Available from: http://medrxiv.org/lookup/;. https:// doi.org/10.1101/2020.04.28.20079582.

6 . The potential impact of the covid-19 response on tuberculosis in high-burden countries: a modelling analysis [Internet]. Stop TB Partnership, Geneva: Stop TB Partnership, Geneva; 2020. Available from: http://www.stoptb.org/assets/ documents/news/Modeling\%20Report_1\%20May\%20 2020_FINAL.pdf.

7. WHO Information note: Tuberculosis and COVID, May, 2020.

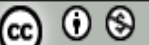

This work is licensed under a Creative Commons AttributionNon Commercial 4.0 International License. 